\title{
Topologically Linked Branch Polymers from Mono-amino-cyclodextrins and Polyethylene Glycol Dicarboxylic Acid
}

\author{
By Kiyoshi TAMURA, Nobuhiro OYA, Kenichi HATANAKA, and Naoko YOSHIE*
}

Topologically linked branch polymers were prepared by condensation of mono-6-deoxy-mono-6-amino cyclodextrin $\left(\mathrm{NH}_{2} \alpha \mathrm{CD}, \mathrm{NH}_{2} \beta \mathrm{CD}\right.$, and $\left.\mathrm{NH}_{2} \gamma \mathrm{CD}\right)$ with polyethylene glycol dicarboxylic acid (PEGdiCOOH). Some $\mathrm{NH}_{2} \mathrm{CD}$ molecules and $\mathrm{PEGdiCOOH}$ chains form inclusion complexes prior to condensation reaction. Since these complexes act as multifunctional monomers, the condensation product contains topologically linked branch polymers, in which $\mathrm{CD}$ rings act both as a topological cross link and as a capping site to prevent dethreading of CD molecules from PEG chains. The formation of a dumbbell shape molecule of CD-PEG-CD was confirmed by NMR analysis. The production of topologically linked branch polymers was confirmed by the multi-modality of size exclusion chromatogram (SEC). The curve resolution of the chromatogram allowed us to estimate the fractions of topologically linked polymers in the products and of the CD molecules threaded on PEG to form topological link. These fractions increase in order of $\gamma \mathrm{CD}<\alpha \mathrm{CD}<\beta \mathrm{CD}$.

KEY WORDS: Topological Polymer / Branch Polymer / Cyclodextrin / Inclusion Complex / Polyethylene Glycol /

Cyclodextrins (CDs) are cyclic oligosaccharides of Dglucopyranose linked by $\alpha$-1,4-linkage. By the number of Dglucopyranose units, they are referred to $\alpha \mathrm{CD}$ (six), $\beta \mathrm{CD}$ (seven), and $\gamma \mathrm{CD}$ (eight). $\mathrm{CD}$ has high potential value as a component of supramolecular systems due to their inclusion ability with molecules of proper size. CD can form inclusion complexes not only with low molecular weight compounds but also with linear polymers. Since the pioneering work on the inclusion complexation between CD and poly(ethylene glycol) (PEG) by Harada et al., ${ }^{1}$ the inclusion complexes of CD with various polymers were synthesized and analyzed. ${ }^{2-9}$ Most of them, however, have paid attention to the inclusion complex obtained as a crystalline precipitate, in which the polymer chains are fully covered with CD molecules. If we can obtain a complex in which $\mathrm{CD}$ rings are sparsely threaded on a polymer chain, the complex would show unique properties because CD rings would freely move along the polymer chain. Ito et al. ${ }^{10,11}$ synthesized topological gel from spare polyrotaxane and demonstrated the significance of the mobility of $\mathrm{CD}$ rings along the polymer chain.

In a previous paper, ${ }^{12}$ we have reported primary results on the condensation of mono-6-deoxy-mono-6-amino $\alpha \mathrm{CD}$ $\left(\mathrm{NH}_{2} \alpha \mathrm{CD}\right)$ and PEG dicarboxylic acid (PEGdiCOOH). Though the main product of this condensation was a simple dumbbell shape molecule of $\alpha \mathrm{CD}-\mathrm{PEG}-\alpha \mathrm{CD}$ (Figure 1a), the product contained topologically-linked branch polymers, in which some CD rings were threaded on PEG chains (Figure 1b). Since these CD rings are sparsely packed onto PEG in the branch polymers, they can move along PEG extensively, giving the polymers some extent of topological flexibility. Further, since the other CD rings do not include a PEG chain in their cavity, they can be used for various applications in the field of host-guest chemistry. In this paper, we describe in-depth structural analysis of the topologically-linked branch polymers synthesized from $\mathrm{NH}_{2} \alpha \mathrm{CD}$ and PEGdiCOOH. The preparations of the topological branch polymers from mono-6-deoxymono-6-amino $\beta \mathrm{CD}\left(\mathrm{NH}_{2} \beta \mathrm{CD}\right)$ and mono-6-deoxy-mono-6amino $\gamma \mathrm{CD}\left(\mathrm{NH}_{2} \gamma \mathrm{CD}\right)$ are also described.

\section{EXPERIMENTAL}

\section{Measurements}

Size exclusion chromatography (SEC) was carried out on a TOSOH HLC-8220 SEC equipped with two Shodex LF-804 SEC columns. PEG standards with low polydispersity were used to construct a calibration curve. $N, N$-dimethylformamide (DMF) containing $0.01 \mathrm{moll}^{-1} \mathrm{LiCl}$ was used as an eluent. The temperature and flow rate were $40^{\circ} \mathrm{C}$ and $1.0 \mathrm{ml} \mathrm{min.}{ }^{-1}$, respectively. Curve fitting of the SEC curves was performed using a least-squares program with the Gauss-Newton iteration procedure.

Mass spectra were recorded with a BIFLEX III TOF mass spectrometer (Bruker) or a Voyeger-DE STR TOF mass spectrometer (PerSeptive Biosystems). An aqueous solution of $\alpha$-cyano-4-hydroxycinnamic acid (as matrix, $10 \mathrm{mg} \mathrm{ml}^{-1}$ ) and sodium trifluoroacetate (as cationating agent, $1 \mathrm{mg} \mathrm{m}^{-1}$ ) was used as a matrix solution. A sample was dissolved in pure water $\left(10 \mathrm{mg} \mathrm{ml}^{-1}\right)$ and mixed with equal volume of the matrix solution. $2 \mu \mathrm{l}$ of the sample solution was spotted on a sample plate, and dried in air at ambient temperature.

$600 \mathrm{MHz}{ }^{1} \mathrm{H}$ NMR spectra and $150 \mathrm{MHz}{ }^{13} \mathrm{C}$ NMR spectra were recorded on a JEOL ECP-600 spectrometer. The spectra were obtained in DMSO-d6. 
(a)
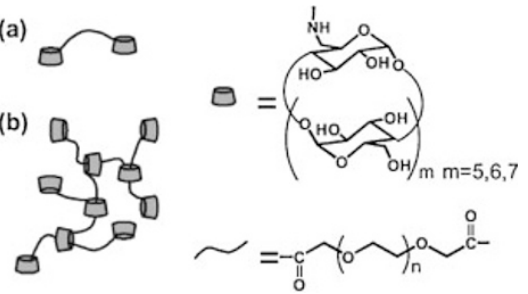

Figure 1. Schematic representation of (a) a simple dumbbell shape molecule and (b) a topologically linked branch polymer consisting of CD and PEG.

\section{Materials}

Unless otherwise described, all agents and solvents were used as received. $\mathrm{NH}_{2} \alpha \mathrm{CD}, \mathrm{NH}_{2} \beta \mathrm{CD}$, and $\mathrm{NH}_{2} \gamma \mathrm{CD}$ were prepared from mono-6-deoxy-mono-6-tosyl $\alpha, \beta$, and $\gamma \mathrm{CD}$, respectively, by a procedure described elsewhere. ${ }^{13}$ PEGdiCOOH (SUNBRIGHT DE-030AC) was purchased from NOF Corp., Japan. From the MALDI TOF mass spectrum, $M_{\mathrm{n}}$ and $M_{\mathrm{w}} / M_{\mathrm{n}}$ of PEGdiCOOH were estimated to be $3.1 \times 10^{3}$ and $\ll 1.1$, respectively (see Figure 5a). Titration of PEGdiCOOH with $0.01 \mathrm{~N} \mathrm{NaOH}$ aqueous solution showed that the amount of - $\mathrm{COOH}$ was $6.7 \times 10^{-4} \mathrm{~mol} \mathrm{~g}^{-1}$, allowing the estimation of $M_{\mathrm{n}}=3.0 \times 10^{3}$. In the ${ }^{1} \mathrm{H}$ NMR spectrum, no sign of chain ends other than $-\mathrm{COOH}$ was observed. Thus, the chain ends of PEGdiCOOH are almost entirely capped with $-\mathrm{COOH}$.

\section{Condensation of $\mathrm{NH}_{2} \mathrm{CD}$ with PEGdiCOOH}

After dissolving $\mathrm{NH}_{2} \mathrm{CD}$ and $\mathrm{PEGdiCOOH}$ ( 0.5 equiv. to $\mathrm{NH}_{2} \mathrm{CD}$ to introduce equimolar $-\mathrm{NH}_{2}$ and $-\mathrm{COOH}$ ) in $\mathrm{DMF}$, the solution was kept at $80^{\circ} \mathrm{C}$ for $3 \mathrm{~h}$ and stirred at ambient temperature for $24 \mathrm{~h}$. Then, 2.4 equiv. of $N, N$-diisopropylethyl amine (DIPEA) and $O$-(benzotriazol-1-yl)- $N, N, N^{\prime}, N^{\prime}$-tetramethyluronium hexafluorophosphate (HBTU) were added as a base and a condensing agent, respectively, and the solution was stirred for $24 \mathrm{~h}$ at ambient temperature. Dialysis by a membrane (molecular cut off was 3500) and lyophilization gave a condensation product.

\section{Fractionation and Acetylation of the Condensation Prod- ucts}

Fractionation of the condensation product $\alpha 15$ was done by Sephadex G-50 using water as an eluent. The last fraction with the lowest molecular weight was acetylated by acetic anhydride in pyridine at $60^{\circ} \mathrm{C}$ for $24 \mathrm{~h}$. The reaction was stopped by addition of water. Evaporation gave a yellow oily crude product. This crude product was dissolved in chloroform, washed with saturated sodium hydrogen carbonate aqueous solution, and dried by magnesium sulfate. Evaporation and drying in vacuo at $50{ }^{\circ} \mathrm{C}$ gave an acetylated product. Completion of the acetylation of $\mathrm{OH}$ groups was confirmed by NMR spectroscopy.

\section{RESULT AND DISCUSSION}

\section{Condensation Reaction of $\mathrm{NH}_{2} \mathrm{CD}$ and PEGdiCOOH}

Topological branch polymers were prepared by the con- densation of $\mathrm{NH}_{2} \mathrm{CD}$ and PEGdiCOOH. In the condensation reaction, the feed ratio of $\mathrm{NH}_{2} \mathrm{CD}$ to $\mathrm{PEGdiCOOH}$ was set to be two in order to introduce equimolar amount of $-\mathrm{NH}_{2}$ and $-\mathrm{COOH}$. This corresponds to the ratio of 33 ethylene glycol (EG) repeating units per one $\mathrm{CD}$ molecule. In order to analyze the effect of the concentration, the reactions were carried out under $\left[\mathrm{NH}_{2} \mathrm{CD}\right]=0.15,0.10,0.05$, and $0.01 \mathrm{moll}^{-1}$. The products are designated as $\chi \mathbf{n n}$, where $\chi$ is the type of CD $(=\alpha, \beta, \gamma)$ and $\mathbf{n n}$ represents the concentration of $\mathrm{NH}_{2} \mathrm{CD}$ $(=15,10,05,01)$ in the reaction solution. For example, in the synthesis of $\alpha 10$, the concentration of $\mathrm{NH}_{2} \alpha \mathrm{CD}$ was 0.10 moll $^{-1}$.

In the synthesis of $\alpha 15$ and $\gamma 15$, small amount of white precipitates appeared after dissolving $0.15 \mathrm{moll}^{-1}$ of $\mathrm{NH}_{2} \alpha \mathrm{CD}$ or $\mathrm{NH}_{2} \gamma \mathrm{CD}$ in DMF with $0.075 \mathrm{moll}^{-1}$ of PEGdiCOOH (the highest concentration we have tried). No precipitates were observed under the other conditions. These precipitates were probably the inclusion complexes of PEGdiCOOH with $\mathrm{NH}_{2} \alpha \mathrm{CD}$ or $\mathrm{NH}_{2} \gamma \mathrm{CD}$. They disappeared after the addition of the condensing agent.

The condensation products were analyzed by ${ }^{1} \mathrm{H}$ and ${ }^{13} \mathrm{C}$ NMR spectroscopy in a manner similar to the previous paper. ${ }^{12}$ In order to avoid unnecessary duplication, only the essence and the additional points of the spectral analysis are given here. Figure $2 \mathrm{a}$ shows the ${ }^{1} \mathrm{H}$ NMR spectrum of $\beta 15$. Figures $2 \mathrm{~b}-\mathrm{d}$ show the expanded spectra of $\alpha 15, \beta 15$, and $\gamma 10$, respectively. The formation of the amide bonds can be confirmed by the chemical-shift change of the chain end methylene, $-\mathrm{CH}_{2}-\mathrm{COOH}$, of $\mathrm{PEGdiCOOH}$ at $4.0 \mathrm{ppm}$. Irrespective of the kinds of $\mathrm{NH}_{2} \mathrm{CD}$, the peak at $4.01 \mathrm{ppm}$ for the unreacted PEGdiCOOH (Figure 2e) shifts to $3.9 \mathrm{ppm}$ for $\alpha 15$, $\beta 15$, and $\gamma 10$. This higher magnetic field shift of $-\mathrm{CH}_{2}-\mathrm{COOH}$ was also observed for the other products irrelevant to the concentration of reactants. Since $N$-ethyl amide of $\mathrm{PEGdiCOOH}$, which was synthesized as a reference compound, has the resonance of $-\mathrm{CH}_{2}-\mathrm{CONH}-$ at $3.84 \mathrm{ppm}$ (data not shown), the peak at $3.9 \mathrm{ppm}$ for the products can be assigned to $P E G-\mathrm{CH}_{2}-\mathrm{CONH}-C D$. In the spectra of the products, no trace of the unreacted $-\mathrm{CH}_{2}-\mathrm{COOH}$ remains, showing that all the chain ends of PEGdiCOOH were reacted.

Since $\mathrm{NH}_{2} \mathrm{CD}$ has $-\mathrm{OH}$ groups in addition to $-\mathrm{NH}_{2}$, the esterification between $\mathrm{NH}_{2} \mathrm{CD}$ and $\mathrm{PEGdiCOOH}$ may proceed in parallel with the amidation. Actually, when unmodified $\alpha \mathrm{CD}$ was kept with PEGdiCOOH under the same reaction condition, the esterification proceeded. Figure $2 f$ shows the expanded spectra of the product from $\alpha \mathrm{CD}$ and PEGdiCOOH. By the reaction with $\alpha \mathrm{CD}$, the peak at $4.0 \mathrm{ppm}$ for $\mathrm{PEGdiCOOH}$ (Figure 2e) disappeared and multiplet peaks appeared at $4.15 \mathrm{ppm}$ (Figure 2f), which can be assigned to $P E G-\mathrm{CH}_{2}-$ COO- $\alpha C D$. Note that the sharp peaks at 4.12 and $4.13 \mathrm{ppm}$ (and the sharp peaks at 2.80 and $2.91 \mathrm{ppm}$ ) are assigned to impurity, probably derived from the condensation agents. ${ }^{14}$ In the NMR spectra of $\alpha 15, \beta 15$, and $\gamma 10$, small trace of multiplet peaks appears around $4.15 \mathrm{ppm}$. Therefore, the ester bond formation can not be entirely ruled out for these products. The peak of the ester bond is, however, much smaller than that of 


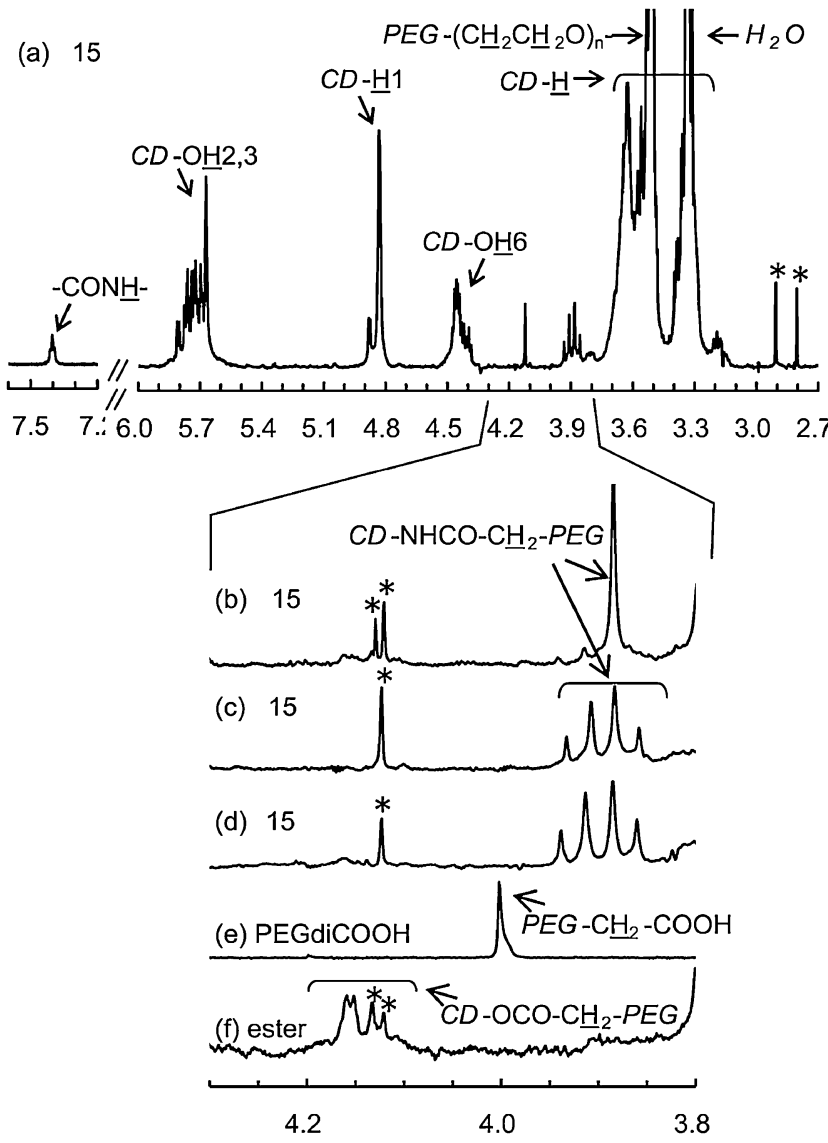

Figure 2. ${ }^{1} \mathrm{H}$ NMR spectra of (a) $\beta 15, \quad$ (b) $\alpha 15$, (c) $\beta 15, \quad$ (d) $\gamma 10$, (e) PEGdiCOOH and (f) a condensation product from $\alpha \mathrm{CD}$ and PEGdiCOOH in DMSO-d6 at $25^{\circ} \mathrm{C}$. The peaks marked with ${ }^{*}$ are assigned to impurity, probably derived from the condensation agents. the amide bond, indicating that the amidation occurs preferentially. Thus, the chemical structure of the products can be regarded as the PEG chains linked by $\mathrm{CD}$ at both chain ends through amide bonds. The influence of the ester bond to the results will be discussed later.

\section{SEC Analysis of Condensation Products from $\mathrm{NH}_{2} \alpha \mathrm{CD}$ and PEGdiCOOH}

The topological structure of the condensation products was analyzed by using SEC. If the products are just a simple dumbbell shape molecule of $\alpha \mathrm{CD}$-PEG- $\alpha \mathrm{CD}$, the SEC curves should have only one narrow peak at the position corresponding to the molecular weight of $\alpha \mathrm{CD}$-PEG- $\alpha \mathrm{CD}$. On the other hand, if the threading of $\mathrm{CD}$ rings onto PEG chains forms topological links, further increase in the average molecular weight and multi-modality in the SEC curves should be observed.

SEC curves of the condensation products were measured in $\mathrm{DMF} / \mathrm{LiCl}$. Note that in our previous paper, ${ }^{12}$ phosphate buffer saline (PBS) was used as an eluent. Since undesirable intermolecular interaction between the condensation products and the SEC columns is reduced, better resolution can be obtained with $\mathrm{DMF} / \mathrm{LiCl}$. The SEC curves of the products measured in $\mathrm{DMF} / \mathrm{LiCl}$ are shown in Figure 3. All the curves show multi-modality, suggesting that the products are not a simple dumbbell shape molecule of $\alpha \mathrm{CD}-\mathrm{PEG}-\alpha \mathrm{CD}$.

The lowest molecular weight component of $\alpha 15$ (Figure 3a, Peak I) was fractionated and analyzed. As shown in the SEC curve of this fraction, fr1, the separation was done well (Figure 4). Though MALDI-TOF mass analysis of fr1 was unsuccessful, full acetylation of $-\mathrm{OH}$ in $\mathbf{f r} \mathbf{1}$ gave the spectrum having a broad peak at $m / z \approx 6400$ (Figure 5 b). Since the mass

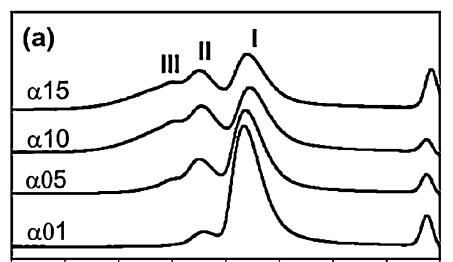

$\begin{array}{lllllllll}14 & 15 & 16 & 17 & 18 & 19 & 20 & 21 & 22\end{array}$ time / min.

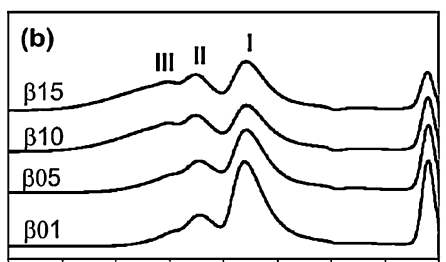

$\begin{array}{lll}14 & 15 & 16\end{array}$

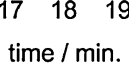

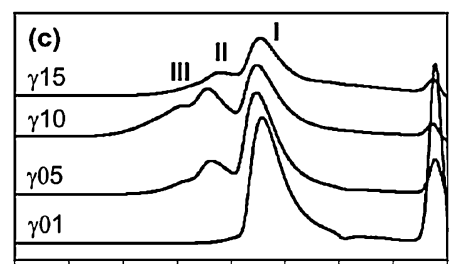

$\begin{array}{lllllllll}14 & 15 & 16 & 17 & 18 & 19 & 20 & 21 & 22\end{array}$

time / $\mathrm{min}$.

Figure 3. SEC elution curves of products from PEGdiCOOH and (a) $\mathrm{NH}_{2} \alpha C D$, (b) $\mathrm{NH}_{2} \beta C D$, and (c) $\mathrm{NH}_{2} \gamma \mathrm{CD}$.

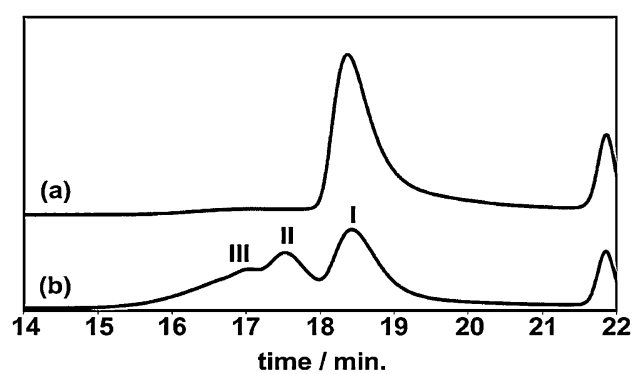

Figure 4. SEC elution curves of (a) fr1 and (b) $\alpha 15$.

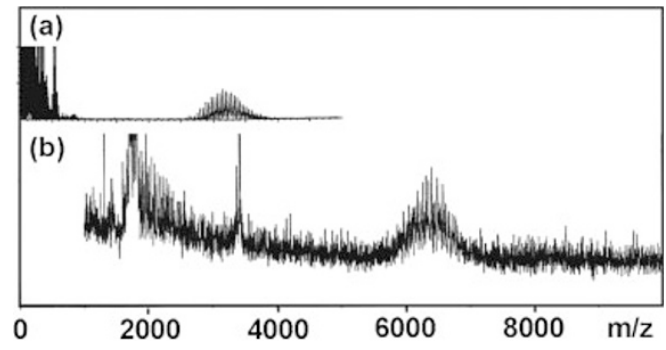

Figure 5. MALDI-TOF mass spectra of (a) PEGdiCOOH and (b) acetylated fr1 of $\alpha 15$. 
Table I. Peak top molecular weight, $M_{\mathrm{p}}$, of peaks I, II, and III in Figure 3

\begin{tabular}{ccccc}
\hline sample code & $M_{\mathrm{p}}(\mathrm{I})$ & $M_{\mathrm{p}}(\mathrm{II})$ & $M_{\mathrm{p}}(\mathrm{III})$ & $M_{\mathrm{p}}(\mathrm{II}) / M_{\mathrm{p}}(\mathrm{I})$ \\
\hline $\boldsymbol{\alpha} 15$ & $4.23 \times 10^{3}$ & $8.28 \times 10^{3}$ & $11.8 \times 10^{3}$ & 1.96 \\
$\beta 15$ & $4.10 \times 10^{3}$ & $8.39 \times 10^{3}$ & $12.4 \times 10^{3}$ & 2.79 \\
$\gamma 15$ & $3.77 \times 10^{3}$ & $6.55 \times 10^{3}$ & $8.66 \times 10^{3}$ & 3.02 \\
$\gamma 10$ & $3.99 \times 10^{3}$ & $8.02 \times 10^{3}$ & $11.9 \times 10^{3}$ & 1.74 \\
\hline
\end{tabular}

of PEGdiCOOH and fully acetylated $\mathrm{NH}_{2} \alpha \mathrm{CD}$ are $\approx 3.1 \times 10^{3}$ (Figure 5a) and 1685, respectively, the mass of the acetylated $\alpha \mathrm{CD}-\mathrm{PEG}-\alpha \mathrm{CD}$ is calculated to be $6.4 \times 10^{3}$. From the ${ }^{1} \mathrm{H}$ NMR analysis, the CD/PEG ratio in fr1 was estimated to be $c a$. 2.0. Thus, fr 1 is confirmed to be the simple dumbbell shape molecule of $\alpha \mathrm{CD}-\mathrm{PEG}-\alpha \mathrm{CD}$ (Figure 1a). Although acetylation was also done for the products before fractionation, MALDI-TOF mass analysis of them was unsuccessful.

From the SEC curves, the peak top molecular weight, $M_{\mathrm{p}}$, relative to linear PEG standards was read from each of the peaks I, II, and III. $M_{\mathrm{p}}(\mathrm{I}), M_{\mathrm{p}}(\mathrm{II})$, and $M_{\mathrm{p}}(\mathrm{III})$ of $\alpha 15$ are 4230 , 8280 , and 11800 , respectively (Table I). $M_{\mathrm{p}}(\mathrm{I})$ is slightly smaller than the calculated molecular weight of the dumbbell shape molecule of $\alpha$ CD-PEG- $\alpha \mathrm{CD}\left(=5.1 \times 10^{3}\right)$. Spherical shape of $\alpha \mathrm{CD}$ should make the relative volume of $\alpha \mathrm{CD}$-PEG$\alpha \mathrm{CD}$ smaller than those of PEG standards. $M_{\mathrm{p}}$ (II) and $M_{\mathrm{p}}(\mathrm{III})$ are twice and three times as high as $M_{\mathrm{p}}(\mathrm{I})$. Therefore, peaks II and III, respectively, can be ascribed to the dimer and trimer of the dumbbell shape molecule, in which one and two topological links are formed by inclusion complexation (Figure 6). It is well known that branching in polymers reduces the hydrodynamic volume and the apparent molecular weight determined by standard SEC. However, in the topological branch polymer, the decrease in the apparent molecular weight is not always the case. The branch points can migrate from the middle to the end of the PEG chain to expand the whole chain

(a)

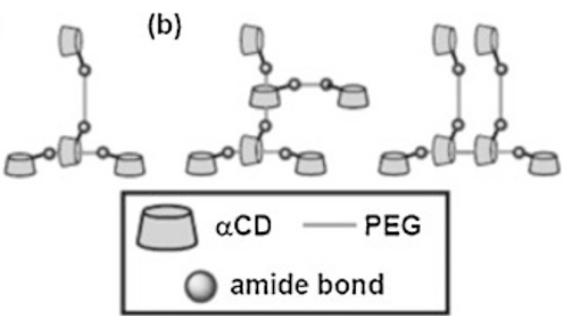

Figure 6. Schematic structures of topological (a) dimer and (b) trimers of the dumbbel shape molecule. as long as linear polymers. Further, our condensation products contain only a few branching points. So, the ratios of the $M_{\mathrm{p}}$ values, $M_{\mathrm{p}}(\mathrm{II}) / M_{\mathrm{p}}(\mathrm{I})$ and $M_{\mathrm{p}}(\mathrm{III}) / M_{\mathrm{p}}(\mathrm{I})$ can be nearly two and three, respectively.

In order to estimate the amount of topologically linked polymers and that of $\alpha \mathrm{CD}$ s threaded on PEG to form topological links, the SEC curves of the products were resolved into Lorenz curves by curve fitting procedure. In the SEC curve of $\alpha 15$, peak III has a broad shoulder on its left side, indicating the existence of topological polymers larger than trimer. Since the peak positions of the larger oligomers cannot be read from the SEC curves, they were calculated based on $M_{\mathrm{p}}(\mathrm{I})$ and the SEC calibration curve. For example, with the assumption that $M_{\mathrm{p}}$ of tetramer is four times as high as $M_{\mathrm{p}}(\mathrm{I})$, the position of the peak IV (for tetramer) was determined from the calibration curve. The peak positions were fixed during the curve fitting procedure. The result of the curve fitting with six curves of the peaks I to VI corresponding to monomer to hexamer is shown in Figure $7 \mathrm{a}$. The relative peak areas are summarized in Table II.

The curve fitting procedure gives the error of $\pm 2.0 \%$. So, the area of the peak VI for $\alpha 15$ is inside the error limits. However, the curve fitting without this peak gave obviously worse result. Thus, the peak VI has some significance. The curve fitting was also done with the seventh peak (for heptamer). Though the curve fitness was certainly improved, the influence in $\mathbf{W}_{\mathbf{t p}}$ and $\mathbf{F}_{\mathrm{tp}}$ (see below) was trivial. Thus, we assumed that the best fit for the SEC curve of $\alpha 15$ was obtained with six curves of the peaks I to VI corresponding to monomer to hexamer. The curve fitting was also carried out for the SEC curves of the other products from $\alpha \mathrm{CD}$ (Table II).

Here, we introduce two parameters representing the topological feature of the condensation products. $\mathbf{W}_{\mathbf{t p}}$ is the weight fraction of topologically linked polymer, which can be estimated as a sum of the relative areas of the peaks II-VI. $\mathbf{F}_{\mathbf{t p}}$ is the fraction of $\alpha \mathrm{CD}$ threaded onto PEG to form topological links, which can also be estimated from the peak areas. Since $n$ mer of $\alpha \mathrm{CD}$-PEG- $\alpha \mathrm{CD}$ has $2 n \mathrm{CD}$ molecules
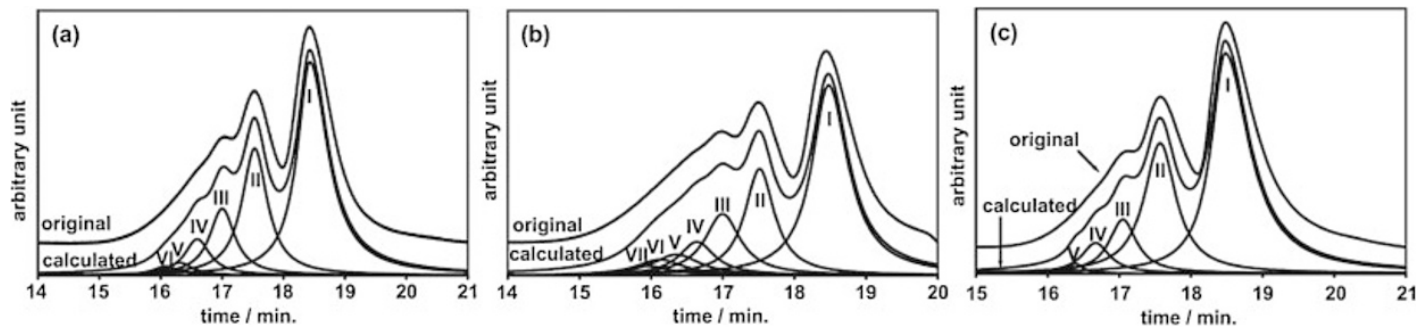

Figure 7. Curve resolution of SEC data of (a) $\alpha 15$, (b) $\beta 15$, and (c) $\gamma 10$. 
Table II. Results of curve resolution for SEC data of the products

\begin{tabular}{|c|c|c|c|c|c|c|c|c|c|}
\hline \multirow[b]{2}{*}{ sample code } & \multicolumn{7}{|c|}{ relative peak area/\% } & \multirow[b]{2}{*}{$\mathrm{W}_{\mathrm{tp}} / \%^{\mathrm{a}, \mathrm{b}}$} & \multirow[b]{2}{*}{$\mathrm{F}_{\mathrm{tp}} / \%^{\mathrm{c}, \mathrm{c}}$} \\
\hline & peak I & peak II & peak III & peak IV & peak V & peak VI & peak VII & & \\
\hline$\alpha 15$ & 49.9 & 25.3 & 13.2 & 7.2 & 2.5 & 1.8 & 0 & 50.0 & 15.2 \\
\hline$\alpha 10$ & 51.3 & 26.8 & 13.6 & 8.8 & 1.7 & 0.8 & 0 & 48.7 & 14.6 \\
\hline$\alpha 05$ & 72.3 & 23.1 & 4.8 & 0 & 0 & 0 & 0 & 27.7 & 7.3 \\
\hline$\alpha 01$ & 82.3 & 7.7 & 0 & 0 & 0 & 0 & 0 & 7.7 & 1.8 \\
\hline$\beta 15$ & 43.4 & 20.7 & 14.2 & 7.8 & 6.3 & 4.7 & 2.9 & 56.6 & 18.5 \\
\hline$\beta 10$ & 42.2 & 22.9 & 16.9 & 7.5 & 4.0 & 3.5 & 3.0 & 57.8 & 18.5 \\
\hline$\beta 05$ & 65.0 & 22.0 & 9.4 & 3.6 & 0 & 0 & 0 & 35.0 & 10.0 \\
\hline$\beta 01$ & 75.2 & 19.3 & 5.5 & 0 & 0 & 0 & 0 & 24.8 & 6.7 \\
\hline$\gamma 10$ & 55.1 & 28.1 & 10.1 & 5.7 & 1.0 & 0 & 0 & 44.9 & 12.9 \\
\hline$\gamma 05$ & 81.1 & 16.0 & 2.9 & 0 & 0 & 0 & 0 & 18.9 & 5.0 \\
\hline$\gamma 01$ & 100.0 & 0 & 0 & 0 & 0 & 0 & 0 & 0 & 0 \\
\hline
\end{tabular}

a; $W_{t p}$ represents the weight fraction of topologically linked branch polymer. $b$; The ester bond formation causes the overestimation in $W_{t p}$. See text for details. c; $F_{t p}$ represents the fraction of CD forming topological links. $d$; The ester bond formation causes the overestimation in $F_{t p}$. The values contains up to $6 \%$ errors. See text for details.

and $n-1$ of $2 n \mathrm{CD}$ molecules form topological links by threading on PEG, $\mathbf{F}_{\text {tp }}$ is the sum of $1 / 4$ of the peak area II (dimer), 2/6 of the peak area III (trimer), 3/8 of the peak area IV (tetramer), 4/10 of the peak area V (pentamer), and 5/12 of the peak VI (hexamer). $\mathbf{W}_{\text {tp }}$ and $\mathbf{F}_{\text {tp }}$ are also summarized in Table II. The errors of these data are estimated to be $\pm 2.0 \%$.

As mentioned above, the formation of the ester bond between $\mathrm{CD}$ and PEGdiCOOH can not be completely ruled out. The ester bond formation causes the overestimation of $\mathbf{W}_{\mathbf{t p}}$ and $\mathbf{F}_{\text {tp. }}$. For example, when $\mathrm{xx} \%$ of $-\mathrm{COOH}$ forms ester bond, apparent $\mathbf{F}_{\text {tp }}$ is estimated to be xx $\%$ over the true percentage of $\mathbf{F}_{\text {tp }}$. However, the spectrum of $\alpha 15$ (Figure 2a) obviously shows that the peak area of the ester bond is much smaller than that of the amide bond. The overestimation in $\mathbf{F}_{\mathbf{t p}}$ given by the ester formation is within a few percent. Combined with the errors from curve fitting $( \pm 2.0 \%)$, the true value of $\mathbf{F}_{\mathbf{t p}}\left(\mathbf{F}_{\mathbf{t p}}{ }^{\mathbf{o}}\right)$ for $\alpha 15$ is between $\mathbf{F}_{\text {tp }}-0.06$ and $\mathbf{F}_{\text {tp }}$. Since $\mathbf{W}_{\text {tp }} / \mathbf{F}_{\text {tp }} \approx 3$, the error in $\mathbf{W}_{\text {tp }}$ should be three times larger than $\mathbf{F}_{\text {tp }}$. Since $\alpha 15$ has the largest ester peak among the condensation products from $\alpha \mathrm{CD}$, the errors for the other product is smaller than this.

After carefully considering the overestimation in $\mathbf{W}_{\mathbf{t p}}$ and $\mathbf{F}_{\text {tp }}$, about $10 \%$ of $\alpha \mathrm{CD}$ forms topological links in $\alpha 15$ to produce about $40 \mathrm{wt} \%$ of topologically linked polymers. $\mathbf{W}_{\text {tp }}$ and $\mathbf{F}_{\text {tp }}$ values decrease as the concentration of reactants decreases. For $\alpha 01$, very small amount of $\alpha \mathrm{CD}$ forms topological links, making a few percent of topologically linked polymers. It is well known that the inclusion complexation between $\mathrm{CD}$ and low molecular weight compounds, such as 4nitropheno ${ }^{15}$ and octyltrimethylammonium bromide, ${ }^{16}$ is dominated by chemical equilibrium. Since the topological links were constructed by threading of $\mathrm{NH}_{2} \alpha \mathrm{CD}$ onto PEGdiCOOH chains, the dependence of $\mathbf{W}_{\text {tp }}$ and $\mathbf{F}_{\mathbf{t p}}$ on the concentration indicates that the inclusion complexation between CD and PEG is also dominated by chemical equilibration.

From the value of $\mathbf{F}_{\mathbf{t p}}$ we can estimate that one out of five PEG chains goes through $\alpha \mathrm{CD}$ in $\alpha 15$. Since one $\alpha \mathrm{CD}$ in the $\mathrm{CD} / \mathrm{PEG}$ inclusion complex can cover two EG repeating units, ${ }^{1}$ PEG chains in the condensation products are only sparsely packed by $\alpha \mathrm{CD}$.

\section{SEC Analysis of Condensation Products from $\mathrm{NH}_{2} \beta C D$ and PEGdiCOOH}

The condensation products from $\mathrm{NH}_{2} \beta \mathrm{CD}$ and PEGdiCOOH also exhibit SEC curves with multi-modality (Figure $3 b$ ). Thus, these products also contain topological links made by inclusion complexation. $M_{\mathrm{p}}$ of the peaks I, II, and III for $\beta 15$ are summarized in Table I. Though $M_{\mathrm{p}}(\mathrm{I})$ of $\beta 15$ $\left(=4.10 \times 10^{3}\right)$ is smaller than the calculated molecular weight of $\beta \mathrm{CD}$-PEG- $\beta \mathrm{CD}$ ( $=5232$ ), the peak I can be ascribed to the dumbbell shape molecule as in the case of $\alpha 15 . M_{\mathrm{p}}(\mathrm{II})$ and $M_{\mathrm{p}}$ (III) are twice and three times as large as $M_{\mathrm{p}}(\mathrm{I})$. Thus, the peaks II and III can be ascribed to the dimer and trimer of $\beta C D-P E G-\beta C D$, respectively.

Following the procedure applied for the $\alpha \mathrm{CD} / \mathrm{PEG}$ products, the SEC curves of the $\beta \mathrm{CD} / \mathrm{PEG}$ products were resolved into lorenzian curves. The result for $\beta 15$ is shown in Figure $7 \mathrm{~b}$. The SEC curve of $\beta 15$ is reproduced with the seven curves of the peaks I to VII, which represents monomer to heptamer of $\beta C D$ PEG- $\beta$ CD having zero to six topological links. The relative areas of the peaks I to VII are summarized with $\mathbf{W}_{\text {tp }}$ and $\mathbf{F}_{\text {tp }}$ in Table II. Similar to the case of the $\alpha \mathrm{CD} / \mathrm{PEG}$ products, the ester bond formation can not be ruled out. However, the ester peaks of $\beta 15$ are obviously smaller than that of $\alpha 15$. Therefore, the errors in $\mathbf{F}_{\mathbf{t p}}$ and $\mathbf{W}_{\mathbf{t p}}$ for the $\beta \mathrm{CD} / \mathrm{PEG}$ products are smaller than those for the $\alpha \mathrm{CD} / \mathrm{PEG}$ products. The true value, $\mathbf{F}_{\mathbf{t p}}{ }^{\mathbf{o}}$, for $\beta 15$ should be between $\mathbf{F}_{\mathbf{t p}}-0.04$ and $\mathbf{F}_{\mathbf{t p}}$.

For the $\beta \mathrm{CD} / \mathrm{PEG}$ products, $\mathbf{W}_{\text {tp }}$ and $\mathbf{F}_{\mathbf{t p}}$ increases with the increase of the concentration of reactants. This result supports our hypothesis that the inclusion complexation between $\mathrm{CD}$ and PEG is dominated by chemical equilibrium. $\mathbf{F}_{\mathbf{t p}}$ of $\beta 15$ is about $15 \%$, indicating one out of three PEG chains is threaded by $\beta \mathrm{CD}$ on average.

Harada et al. ${ }^{2}$ have reported that the procedure that worked for the preparation of the crystalline $\alpha \mathrm{CD} / \mathrm{PEG}$ complex does not work for the $\beta \mathrm{CD} / \mathrm{PEG}$ system. They attributed this unavailability of the crystalline complex to the small binding constant for the complexation of $\beta \mathrm{CD}$ with PEG. Recently, however, Udachin et al. ${ }^{17}$ have succeeded in the preparation of the crystalline $\beta \mathrm{CD} / \mathrm{PEG}$ complex. Though they mentioned 
the difficulty of the preparation of the $\beta C D / P E G$ inclusion complex compared to the $\alpha \mathrm{CD} / \mathrm{PEG}$ complex, they clearly shown that $\beta C D$ certainly forms the inclusion complex with PEG. Our result shows that $\beta \mathrm{CD}$, as well as $\alpha \mathrm{CD}$, forms the soluble inclusion complex with PEG in solution. Though this result has no direct connection with the results of Harada et al. ${ }^{2}$ and Udachin et al. ${ }^{17}$ on the crystalline complex, a compatible explanation for all of these results is that the soluble $\beta C D / P E G$ complex, in which PEG is sparsely covered with $\beta C D$ molecule, is formed easier than the insoluble one, in which PEG is fully covered with $\beta C D$.

$\mathbf{W}_{\text {tp }}$ and $\mathbf{F}_{\text {tp }}$ for $\beta \mathrm{CD} / \mathrm{PEG}$ are slightly higher than those of $\alpha \mathrm{CD} / \mathrm{PEG}$, which implies that $\beta \mathrm{CD}$ has larger binding constant for the complexation with PEG than $\alpha \mathrm{CD}$ in DMF. However, this may not true. Yamada et al. ${ }^{18}$ and Jullien et al. ${ }^{19}$ reported that the substituents of CD with proper size are included in the cavity of the linked $\mathrm{CD}$ to form intramolecular complexes. In our case, during the condensation reaction, $-\mathrm{NH}_{2}$ of the $\mathrm{CD}$ ring forming an inclusion complex is closer to $-\mathrm{COOH}$ of the threaded PEG chain than those of the other chains. So, they are susceptible to react with each other to form an intramolecular inclusion complex. The CD ring forming intramolecular complexes do not work as a topological link but as a chain end. The difference in the ring size may affect the reactivity between $\mathrm{CD}$ and PEG in the inclusion complex. The narrower $\alpha \mathrm{CD}$ ring may gives more chance to the threaded $\mathrm{PEG}$ to react to form intramolecular complexes. If this is the case, $\mathbf{F}_{\text {tp }}$ of $\beta \mathrm{CD} /$ PEG can be larger than that of $\alpha \mathrm{CD} / \mathrm{PEG}$ even if they have the same binding constants for the complexation. The study on the intramolecular complexation is under investigation.

\section{SEC Analysis of the Products from $\mathrm{NH}_{2} \gamma \mathrm{CD}$ and PEGdiCOOH}

The condensation products from $\mathrm{NH}_{2} \gamma \mathrm{CD}$ and PEGdiCOOH also exhibit SEC curves with multi-modality (Figure 3c). Thus, these products contain topological links made by inclusion complexation. $M_{\mathrm{p}}$ of $\gamma 10$ and $\gamma 15$ are summarized in Table I. For $\gamma 10, M_{\mathrm{p}}$ (II) and $M_{\mathrm{p}}(\mathrm{III})$ are twice and three times as large as $M_{\mathrm{p}}(\mathrm{I})$. Thus, peaks II and III can be ascribed to the dimer and trimer of the dumbbell shape molecule of $\gamma$ CD-PEG- $\gamma$ CD. The peak positions for $\gamma 05$ and $\gamma 01$ are similar to those of $\gamma 10$. On the other hand, $M_{\mathrm{p}}(\mathrm{II})$ and $M_{\mathrm{p}}$ (III) of $\gamma 15$ are obviously smaller than those of $\gamma 10$ though $M_{\mathrm{p}}$ (I) of them are similar (Table II). Further, contrary to the case of the $\alpha \mathrm{CD} / \mathrm{PEG}$ and $\beta \mathrm{CD} / \mathrm{PEG}$ products, the area of the higher molecular weight peaks (peaks other than peak I) does not increases with the concentration of reactants for the $\gamma \mathrm{CD} /$ PEG products. $\gamma 10$ apparently shows the maximum. This result suggests that topological structure of $\gamma 15$ is different from that of $\gamma 10, \gamma 05$, and $\gamma 01$. Harada et al. ${ }^{20}$ reported that $\gamma \mathrm{CD}$ can include two PEG chains in its cavity. Some $\gamma \mathrm{CD}$ in $\gamma 15$ may also include two PEG chains, giving more complex topological structure.

The SEC curves of the products from $\mathrm{NH}_{2} \gamma \mathrm{CD}$ and PEGdiCOOH were resolved into Lorenz curves by curve fitting procedure. The result for $\gamma 10$ is shown in Figure $7 \mathrm{c}$. The
SEC curve was resolved into five peaks, which represent monomer to pentamer of the dumbbell shape molecule of $\gamma \mathrm{CD}$ PEG- $\gamma$ CD having zero to four topological links. Because of the complex nature of the SEC curve discussed above, the curve fitting cannot be done for $\gamma 15$. The relative peak areas for $\gamma 10$, $\gamma 05$, and $\gamma 01$ are summarized with $\mathbf{W}_{\text {tp }}$ and $\mathbf{F}_{\text {tp }}$ in Table II. Considering the possibility of the ester bond formation, the errors in $\mathbf{F}_{\mathbf{t p}}$ and $\mathbf{W}_{\mathbf{t p}}$ for the products from $\gamma \mathrm{CD}$ are as low as those for the products from $\beta \mathrm{CD}$. $\mathbf{W}_{\mathbf{t p}}$ and $\mathbf{F}_{\text {tp }}$ increase with the increase of the concentration of reactants from $\gamma 01$ to $\gamma 10$, indicating again that the inclusion complexation between CD and PEG is dominated by equilibrium. $\mathbf{F}_{\mathbf{t p}}$ of $\gamma 10$ is about $10 \%$, showing one out of five PEG chains go through $\gamma \mathrm{CD}$. $\mathbf{W}_{\text {tp }}$ and $\mathbf{F}_{\mathbf{t p}}$ of $\gamma \mathrm{CD}$ are slightly smaller than that of $\alpha \mathrm{CD}$.

\section{CONCLUSION}

In this paper, the preparation and characterization of topologically linked branch polymers from $\mathrm{NH}_{2} \mathrm{CD}$ with PEGdiCOOH were described. By the condensation reaction between $-\mathrm{NH}_{2}$ of $\mathrm{NH}_{2} \mathrm{CD}$ and $-\mathrm{COOH}$ of $\mathrm{PEGdiCOOH}, \mathrm{CD}$ was attached to chain ends of PEG to form a dumbbell shape molecule of CD-PEG-CD. SEC analysis shows that the condensation product is not a simple dumbbell shape molecule, but contains topologically linked branch polymers. In the condensation product, up to $50 \mathrm{wt} \%$ of the products are topologically linked polymers and up to $15 \%$ of $\mathrm{CD}$ molecules form topological links.

The previous papers on the $\alpha \mathrm{CD} / \mathrm{PEG}$ inclusion compel $\mathrm{x}^{1,6}$ mainly focused on the complex obtained as precipitates, in which CD molecules are densely packed on PEG chains. On the other hand, our results show that the sparsely threaded inclusion complex of $\mathrm{CD} / \mathrm{PEG}$ is formed in solution as a soluble component and that this kind of sparsely threaded polymers can be used for construction of topologically linked molecular systems.

Unfortunately, we have obtained the polymers with only a few topological branches. So, the samples do not show significant properties characteristic of topological polymers. However, if we can prepare the complex where more CDs (1-2 CD per 1 PEG) are threaded on PEG, we would obtain topological hyperbranched polymers and topological gels with novel properties.

Received: January 18, 2008 Accepted: March 12, 2008 Published: April 23, 2008

\section{REFERENCES AND NOTES}

1. A. Harada and M. Kamachi, Macromolecules, 23, 2821 (1990).

2. A. Harada, M. Okada, J. Li, and M. Kamachi, Macromolecules, 28, 8406 (1995).

3. L. Huang, E. Allen, and A. E. Tonelli, Polymer, 39, 4857 (1998).

4. Y. Kawaguchi, T. Nishiyama, M. Okada, M. Kamachi, and A. Harada, Macromolecules, 33, 4472 (2000).

5. F. Cacialli, J. S. Wilson, D. L. Michels, C. Silva, R. H. Friend, N. Severin, P. Samori, J. P. Rabe, M. J. O'connell, P. Taylor, and H. 
Anderson, Nat. Mat., 1, 160 (2002).

6. T. Ikeda, W. K. Lee, T. Ooya, and N. Yui, J. Phys. Chem. B, 107, 14 (2003).

7. C. C. Rusa, X. Shuai, I. D. Shin, T. A. Bullions, M. Wei, F. E. Porbeni, J. Lu, L. Huang, J. Fox, and A. E. Tonelli, Polym. Environ., 12, 157 (2004).

8. M. Okada, Y. Takashima, and A. Harada, Macromolecules, 37, 7075 (2004).

9. N. Kihara, K. Hinoue, and T. Takata, Macromolecules, 38, 223 (2005).

10. Y. Okumura and K. Ito, Adv. Mater., 13, 485 (2001).

11. J. Araki, C. Zhao, and K. Ito, Macromolecules, 38, 7524 (2005).

12. K. Tamura, K. Hatanaka, and N. Yoshie, Polym. Int., 56, 1115 (2007).

13. L. D. Melton and K. N. Slessor, Carbohydr. Res., 18, 29 (1971).

14. We have synthesized the dumbbell shape molecule of $\alpha \mathrm{CD}-\mathrm{PEG}-$ $\alpha \mathrm{CD}$ (shown in Figure 1a) by the deacetylation of the condensation product of PEGdiCOOH with mono-6-deoxy-mono-6-azide O-acetyl $\alpha \mathrm{CD}$ (K. Tamura, K. Hatanaka, N. Yoshie unpublished results). Since all the $\mathrm{OH}$ groups of $\alpha \mathrm{CD}$ were protected by acetyl groups during this condensation, the ester bond between $-\mathrm{OH}$ of $\alpha \mathrm{CD}$ and $-\mathrm{COOH}$ of PEGdiCOOH cannot be formed. Despite this, the ${ }^{1} \mathrm{H}$ NMR spectrum of this product also had the peaks at 2.80, 2.91, 4.12 and $4.13 \mathrm{ppm}$. Therefore, these peaks are irrelevant to the presence or absence of the ester bond between $\mathrm{CD}$ and $\mathrm{PEGdiCOOH}$.

15. Y. Kanda, Y. Yamamoto, Y. Inoue, R. Chujo, and S. Kobayashi, Bull. Chem. Soc. Jpn., 62, 2002 (1989).

16. N. Funasaki, S. Ishikawa, and S. Neya, J. Phys. Chem. B, 107, 10094 (2003).

17. K. A. Udachin, L. D. Wilson, J. A. Ripmeester, J. Am. Chem. Soc., 122, 12375 (2000).

18. T. Yamada, G. Fukuhara, and T. Kaneda, Chem. Lett., 32, 534 (2003).

19. L. Jullien, J. Canceill, L. Lacomb, and J. M. J. Lehn, Chem. Soc. Perkin Trans, 2, 989 (1994).

20. A. Harada, J. Li, and M. Kamachi, Nature, 370, 126 (1994). 